\title{
Evaluasi Nilai Stabilitas dan Flow Campuran AC-BC Pada Penggunaan Alat Uji Marshall Analog dan Digital ${ }^{1}$
}

\section{Evaluation of AC-BC Mixtures Stability and Flow Values on the Use of Analog and Digital Marshall Test Equipment}

\author{
Sonya Sulistyono ${ }^{\mathrm{a}}$, Ririn Endah Badriani ${ }^{\mathrm{b}}$, Zakaria $^{\mathrm{c},}$ \\ ${ }^{a}$ Staf Pengajar Jurusan Teknik Sipil, Fakultas Teknik, Universitas Jember, Jl. Kalimantan 37 Jember, email: \\ sonya.sulistyono@unej.ac.id \\ ${ }^{\mathrm{b}}$ Staf Pengajar Jurusan Teknik Sipil, Fakultas Teknik, Universitas Jember, Jl. Kalimantan 37 Jember, email: \\ ririndidin@gmail.com \\ ${ }^{\mathrm{c}}$ Mahasiswa Jurusan Teknik Sipil, Fakultas Teknik, Universitas Jember, Jl. Kalimantan 37 Jember, email: \\ zakaria.usman007@gmail.com
}

\begin{abstract}
ABSTRAK
Alat uji Marshall digunakan untuk mengetahui stabilitas terhadap kelelehan plastis (flow) dan $M Q$ dari lapis perkerasan $A C-B C$. Tipe alat pengujian Marshall dapat berupa analog dan digital. Alat uji analog dengan pembacaan data manual sangat bergantung pada ketrampilan operator. Alat uji digital menggunakan sistem komputer, sehingga menghasilkan data maksimum dengan operator minimum. Penelitian dilaksanakan berdasarkan SNI 06-2489-1991 pada campuran $A C-B C$ dengan lima variasi kadar aspal. Hasil pengujian didapatkan nilai rata-rata alat uji analog pengamatan langsung: stabilitas $(\mathrm{kg})=1490,49 ;$ Flow $(\mathrm{mm})=4,48$; $M Q(\mathrm{~kg} / \mathrm{mm})=335,55$. Alat uji analog pengamatan perekaman video: stabilitas $(\mathrm{kg})=1482,91 ;$ Flow $(\mathrm{mm})=$ 4,44; $M Q(\mathrm{~kg} / \mathrm{mm})=336,48$. untuk alat uji digital menghasilkan stabilitas $(\mathrm{kg})=1508,36 ;$ Flow $(\mathrm{mm})=$ 4,$42 ; M Q(\mathrm{~kg} / \mathrm{mm})=342,93$. Berdasarkan analisa perbedaan tiga rata-rata menunjukkan tidak terdapat perbedaan signifikan hasil pengujian menggunakan alat uji Marshall analog pengamatan langsung, perekaman video dan digital.
\end{abstract}

Kata kunci: campuran AC-BC, karakteristik Marshall, alat uji marshall analog dan digital

\begin{abstract}
Marshall test-equipment is used to determine the stability of the flow and MQ of AC-BC pavement. It can be an analog and a digital test-equipment. Analog test-equipment reading the data manually dependens on the operator skills. While the digital test equipment uses a computer system produces maximum data with minimum operator. The research is conducted based on a mixture SNI 06-2489-1991 AC-BC with five variation of asphalt content. The presumptions of the test result of Marshall characteristic are found out as: the direct observation-analogue gets the stability $(\mathrm{kg})=1490.49$; Flow $(\mathrm{mm})=4.48 ; \mathrm{MQ}(\mathrm{kg} / \mathrm{mm})=$ 335.55. The visualization analogue gets the stability $(\mathrm{kg})=1482.91$; Flow $(\mathrm{mm})=4.44 ; \mathrm{MQ}(\mathrm{kg} / \mathrm{mm})=$ 336.48. The digital test-equipment gets the stability $(\mathrm{kg})$ 1508.36; Flow $(\mathrm{mm})=4.42$; $\mathrm{MQ}(\mathrm{kg} / \mathrm{mm})=$ 342.93. Based on the three different analysis evenly show that there are no different significantly from the test result by using the direct observation-analogue, the visualization analogue, and the digital Marshall testequipment.
\end{abstract}

Keywords: AC-BC mixtures, Marshall charactheristik, analog and digital Marshall test equipment 


\section{PENDAHULUAN}

Alat Uji Marshall digunakan untuk mengetahui karakteristik suatu lapis perkerasan jalan. Salah satu alat pengujian Marshall yang masih banyak digunakan di laboratorium adalah alat uji Marshall analog. Alat uji tersebut dalam pembacaan dial nilai stabilitas dan flow hasil pengujian, masih menggunakan keterampilan dari oprator. Karena di pembacaan alat analog ini sangat membutuhkan kercermatan dan ketelitian yang tinggi. maka disini saya akan membandingkan hasil dari pembacaan stabilitas dan flow ini dengan cara membandingkan pengamatan langsung dan perekaman video bertujuan membandingkan dampak kesalahan yang diakibatkan oleh faktor manusia yaitu kelalaian, kelelahan dan kondisi psikologis operator. Akibatnya dapat mempengaruhi tingkat kecepatan dan akurasi data yang dihasilkan.

Dari penelitian $A C$ - $B C$ sebelumnya yang di lakukan Aditama (2014), dan penelitian $A C$ $W C$ yang di lakukan Zulfikar (2014), Hasil pengujian keduanya ( $A C-B C$ dan $A C-W C$ ) menunjukan tidak berbeda signifikan, namun pengujian sebelumnya hanya mengunakan 1 (satu) varian kadar aspal dan pembacaan dial analog menggunakan bantuan perekaman video sehingga hasil pembacaan tidak full dari ketelitian oprator sedangkan di laboratorium masi jarang menggunakan metode perekaman. Sehingga dalam penelitian kali ini akan menggunakan beberapa varian kadar aspal dan untuk pembacaan dial analog akan melakukan pengamatan langsung dan bantuan perekaman video.

Seiring dengan kemajuan teknologi alat uji marshall dikembangkan secara inovatif dan komersial menggunakan sistem komputer, salah satunya adalah alat uji Marshall digital. Berbeda dengan alat uji analog, Alat uji Marshall digital menggunakan sistem komputer sehingga menghasilkan data maksimum dengan operator minimum. Alat tersebut bekerja dengan cara dihubungkan langsung pada perangkat lunak di sebuah sistem komputer. Komputer tersebut selanjutnya digunakan untuk menginput, mengontrol, melaksanakan dan mengolah data hasil pengujian Marshall secara digital. Sehingga dapat mengurangi kesalahan yang diakibatkan oleh faktor manusia.

Penggunaan alat uji analog (pengamatan langsung dan pengamatan perekaman video) dan digital dalam pengujian Marshall akan memberikan kecepatan dan akurasi data sesuai kemampuannya. Untuk itu evaluasi karakteristik Marshall menggunakan alat uji Marshall analog (pengamatan langsung dan pengamatan perekaman video) dan digital perlu dilakukan. Evaluasi yang dilakukan adalah membandingkan hasil pengujian alat uji analog (pengamatan langsung dan pengamatan perekaman video) dan digital, apakah ada perbedaan secara signifikan atau tidak. Kemudian menganalisa pendugaan hasil pengujian menggunakan alat uji Marshall analog (pengamatan langsung dan pengamatan perekaman video) dan digital. Penelitian dilakukan dengan melaksanakan pengujian Marshall pada varian kadar aspal panas Asphalt Concrete - Binder Course (AC-BC).

\section{METODE PENELITIAN}

\section{Lokasi Penelitian}

Penelitian ini dilakukan Laboratorium Transportasi - Jurusan Teknik Sipil - Fakultas Teknik Universitas Jember. 


\section{Alat Pengujian Marshall}

Alat Marshall merupakan alat penguji benda uji untuk menentukan nilai stabilitas, flow dan $M Q$. Alat tekan ini dilengkapi dengan proving ring (cincin penguji) berkapasitas $22,2 \mathrm{KN}$ atau setara 5000lbf untuk menguji stabilitas dan flowmeter untuk mengukur kelelehan plastis atau flow. Benda uji Marshall berbentuk silinder berdiameter 4 inci atau setara 10,2 $\mathrm{cm}$ dan tinggi 2,5 inci atau setara 6,35 cm. (Silvia Sukirman, 2003).

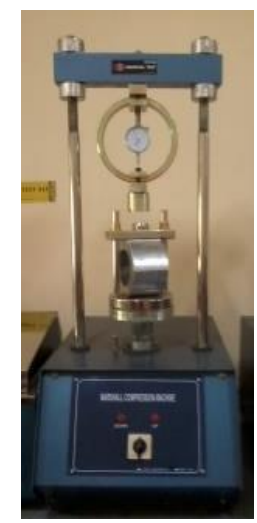

Gambar 1. Alat Uji Analog

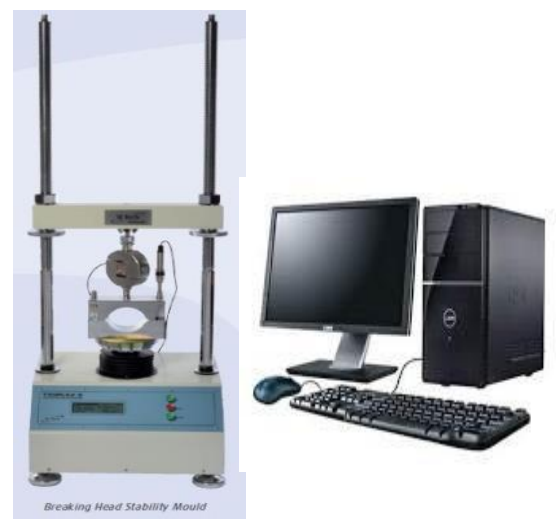

Gambar 2. Alat Uji Digital

\section{Tahapan Pelaksanaan penelitian}

Tahapan dalam pelaksanaan penelitian dilakukan sebagai berikut:

1. Uji pendahuluan: pengujian bahan (agregat kasar, halus, filler dan aspal pen 60/70), perencanaan komposisi campuran, pembuatan benda uji, karakteristik volumetrik.

2. Membandingkan karakteristik volumetri benda uji.

3. Pengujian Marshall menggunakan alat uji Marshall analogdan digital.

4. Analisa Perbedaan Tiga Rata-rata.

5. Pendugaan hasil pengujian.

6. Kesimpulan dan saran.

\section{Hipotesa}

Tidak ada perbedaan secara signifikan pada hasil pengujian Marshall menggunakan alat uji Marshall analog dan digital $(\mu 1=\mu 2=\mu 3)$ pada campuran Asphalt Concrete - Binder Course $(A C-B C)$.

Keterangan :

$\mu 1$ : Rata-rata hasil pengujian menggunakan alat uji analog pengamatan langsung.

$\mu 2$ : Rata-rata hasil pengujian menggunakan alat uji analog pengamatan perekaman video.

$\mu 3$ : Rata-rata hasil pengujian menggunakan alat uji digital.

\section{Analisa Data}

Untuk menganalisis dan mengolah data hasil pengujian karakteristik Marshall, digunakan analisa uji Anova. Analisa uji Anova berfungsi untuk menguji hipotesis dan membuat pendugaan parameter dari tiga populasi. Untuk pengujian uji Anova ditunjukkan sebagai berikut: 


\section{Pengujian Perbedaan Tiga Rata-rata}

Pengujian dilakukan untuk menguji kebenaran atau kepalsuan hipotesis nol, apakah ada perbedaan yang signifikan atau tidak. Untuk menguji hipotesis dapat dilakukan dengan langkah (Supranto, 2009) berikut:

1. Mencari nilai rata-rata sampel yang diteliti

$$
\mathrm{X}=\frac{1}{n} \sum X i=\frac{1}{n}(\mathrm{X} 1+\mathrm{X} 2+\cdots \mathrm{Xn})
$$

2. Menghitung nilai standart deviasi

$$
\begin{aligned}
& s=\sqrt{\frac{1\left(\sum(X i-X)^{2}\right)}{n-1}} \\
& \mathrm{~S}_{x}=\sqrt{\frac{s}{\sqrt{n}}}
\end{aligned}
$$

3. Merumuskan hipotesis

$\mathrm{H} 0: \mu 1-\mu 2-\mu 3=0(\mu 1=\mu 2)$, maka hipotesis $\mathrm{H} 0$ diterima

$\mathrm{H} 1: \mu 1-\mu 2-\mu 3 \neq 0(\mu 1 \neq \mu 2)$, maka hipotesis $\mathrm{H} 1$ diterima

4. Pengujian hipotesis dengan Perbedaan Tiga Rata-rara

$$
F_{0}=\frac{V_{A}}{V_{D}}=\frac{J K_{A}}{J K_{D}}=\frac{\text { Varian Antara Group }}{\text { Varian Dalam Group }}
$$

5. Jika nilai $\mathrm{f}_{\text {hitung }} \geq \mathrm{f}_{\text {tabel }}$ maka $\mathrm{HO}$ ditolak, artinya ada perbedaan yang signifikan dari hasil pengujian menggunakan alat uji analog dan alat uji digital. Jika $\mathrm{f}_{\text {hitung }} \leq \mathrm{f}$ tabel maka H0 diterima, artinya tidak ada perbedaan yang signifikan dari hasil pengujian menggunakan alat uji analog dengan alat uji digital.

\section{Pendugaan Hasil Pengujian}

Pengujian dilakukan untuk mencari pendugaan nilai berupa interval yang dibatasi oleh dua nilai, yaitu nilai batas bawah dan batas atas. Untuk menguji pendugaan hasil pengujian dapat dilakukan dengan langkah (Supranto, 2009) berikut:

1. Menentukan rata-rata sampel

$$
\mathrm{X}=\frac{1}{n} \sum X i=\frac{1}{n}(\mathrm{X} 1+\mathrm{X} 2+\cdots \mathrm{Xn})
$$

2. Menentukan tingkat kesalahan sebesar $5 \%$ atau probabilitas sebesar $95 \%$.

3. Menentukan standart deviasi

$$
\begin{aligned}
& s=\sqrt{\frac{1\left(\Sigma(X i-X)^{2}\right)}{n-1}} \\
& s=\sqrt{\frac{s}{\sqrt{n}}}
\end{aligned}
$$

4. Menghitung nilai pendugaan hasil pengujian

$$
\mathrm{X}-\mathrm{f} \alpha / 2 \frac{s}{\sqrt{n}}<\mu<\mathrm{X}+\mathrm{f} \alpha / 2 \frac{s}{\sqrt{n}}
$$

\section{HASIL DAN PEMBAHASAN}

\section{Karakteristik Volumetrik Benda Uji}

Uji karakteristik volumetrik dilakukan untuk mengetahui apakan benda uji yang akan di ujikan pada alat uji analog dan digital memiliki kemiripan karakteristik volumetrik Density, VMA, VMA, VFA sehingga mengurangi berbedaan hasil uji marshall yang di 
sebabkan oleh berbedanya benda uji. Untuk hasil perbandingan dan analisa karakteristik volumetrik dapat dilihat di tabel 1 .

Tabel 1. Karakteristik Volumetrik

\begin{tabular}{|c|c|c|c|c|c|c|c|c|c|c|}
\hline \multirow{2}{*}{$\begin{array}{c}\text { Kadar } \\
\text { Aspal } \\
(\%)\end{array}$} & \multicolumn{2}{|c|}{ Benda Uji } & \multicolumn{2}{|c|}{ Analog } & \multicolumn{2}{|c|}{ Digital } & \multirow[b]{2}{*}{ Alfa } & \multirow{2}{*}{$\begin{array}{c}\text { F } \\
\text { Hitung }\end{array}$} & \multirow{2}{*}{$\underset{\text { Kritis }}{\text { F }}$} & \multirow[b]{2}{*}{ Ket. } \\
\hline & Volumetrik & Jumlah & $\begin{array}{c}\text { Rata- } \\
\text { rata }\end{array}$ & Deviasi & $\begin{array}{c}\text { Rata- } \\
\text { rata }\end{array}$ & Deviasi & & & & \\
\hline 4,3 & & 5 & 2,228 & 0,011 & 2,235 & 0,010 & 0,05 & 0,739 & 5,318 & diterima \\
\hline 4,8 & & 5 & 2,236 & 0,012 & 2,237 & 0,011 & 0,05 & 0,006 & 5,318 & diterima \\
\hline 5,3 & Density & 5 & 2,250 & 0,011 & 2,248 & 0,011 & 0,05 & 0,031 & 5,318 & diterima \\
\hline 5,8 & & 5 & 2,279 & 0,010 & 2,276 & 0,010 & 0,05 & 0,221 & 5,318 & diterima \\
\hline 6,3 & & 5 & 2,341 & 0,016 & 2,339 & 0,018 & 0,05 & 0,042 & 5,318 & diterima \\
\hline 4,3 & & 5 & 10,590 & 0,417 & 10,316 & 0,443 & 0,05 & 0,739 & 5,318 & diterima \\
\hline 4,8 & & 5 & 9,659 & 0,472 & 9,632 & 0,455 & 0,05 & 0,006 & 5,318 & diterima \\
\hline 5,3 & VIM & 5 & 8,505 & 0,433 & 8,566 & 0,448 & 0,05 & 0,031 & 5,318 & diterima \\
\hline 5,8 & & 5 & 6,719 & 0,389 & 6,863 & 0,398 & 0,05 & 0,221 & 5,318 & diterima \\
\hline 6,3 & & 5 & 3,564 & 0,652 & 3,676 & 0,729 & 0,05 & 0,016 & 5,318 & diterima \\
\hline 4,3 & & 5 & 20,451 & 0,371 & 20,208 & 0,394 & 0,05 & 0,739 & 5,318 & diterima \\
\hline 4,8 & & 5 & 20,155 & 0,418 & 20,131 & 0,402 & 0,05 & 0,006 & 5,318 & diterima \\
\hline 5,3 & VMA & 5 & 19,662 & 0,381 & 19,715 & 0,394 & 0,05 & 0,031 & 5,318 & diterima \\
\hline 5,8 & & 5 & 18,618 & 0,339 & 18,744 & 0,347 & 0,05 & 0,221 & 5,318 & diterima \\
\hline 6,3 & & 5 & 16,396 & 0,565 & 16,494 & 0,632 & 0,05 & 0,016 & 5,318 & diterima \\
\hline 4,3 & & 5 & 48,235 & 1,119 & 48,964 & 1,159 & 0,05 & 0,756 & 5,318 & diterima \\
\hline 4,8 & & 5 & 52,095 & 1,375 & 52,176 & 1,290 & 0,05 & 0,006 & 5,318 & diterima \\
\hline 5,3 & VFA & 5 & 56,765 & 1,369 & 56,572 & 1,433 & 0,05 & 0,031 & 5,318 & diterima \\
\hline 5,8 & & 5 & 63,933 & 1,411 & 63,406 & 1,447 & 0,05 & 0,225 & 5,318 & diterima \\
\hline 6,3 & & 5 & 78,377 & 3,105 & 77,797 & 3,625 & 0,05 & 0,018 & 5,318 & diterima \\
\hline
\end{tabular}

Berdasarkan tabel 1, dari perbandingan karakteristik volumetrik Density, VIM, VMA, dan $V F A$ menujukan bahwa rata-rata dari setiap kadar aspal memilik kemiripan volumentrik, pada standart deviasi juga bisa dikatan memiliki kemiripan karena perbedaan standart deviasi antara benda uji analog dan benda uji digital memiliki berbedaan yang sangat kecil. Pada analisa statistik juga menunjukan $F_{\text {hitung }}$ lebih kecil daripada $F_{\text {tabel }}$ sehingga benda uji bisa dikatakan tidak berbeda signifikan, sehingga benda uji siap untuk di uji dengan mengunakan alat uji marshall analog dan uji marshall digital.

\section{Karakteristik Marshal Pengujian Menggunakan Alat Uji Analog dan Digital}

Pengujian mengunakan alat uji marshal menghasilkan tiga sifat campuran karakteristik Marshall di dalam beton aspal padat yaitu stabilitas, flow, $M Q$. Dari hasil pengujian sebanyak lima benda uji pada setiap alat uji analog dan digital didapatkan nilai perbandingan karakteristik Marshall seperti pada gambar 3, 4, dan 5. 


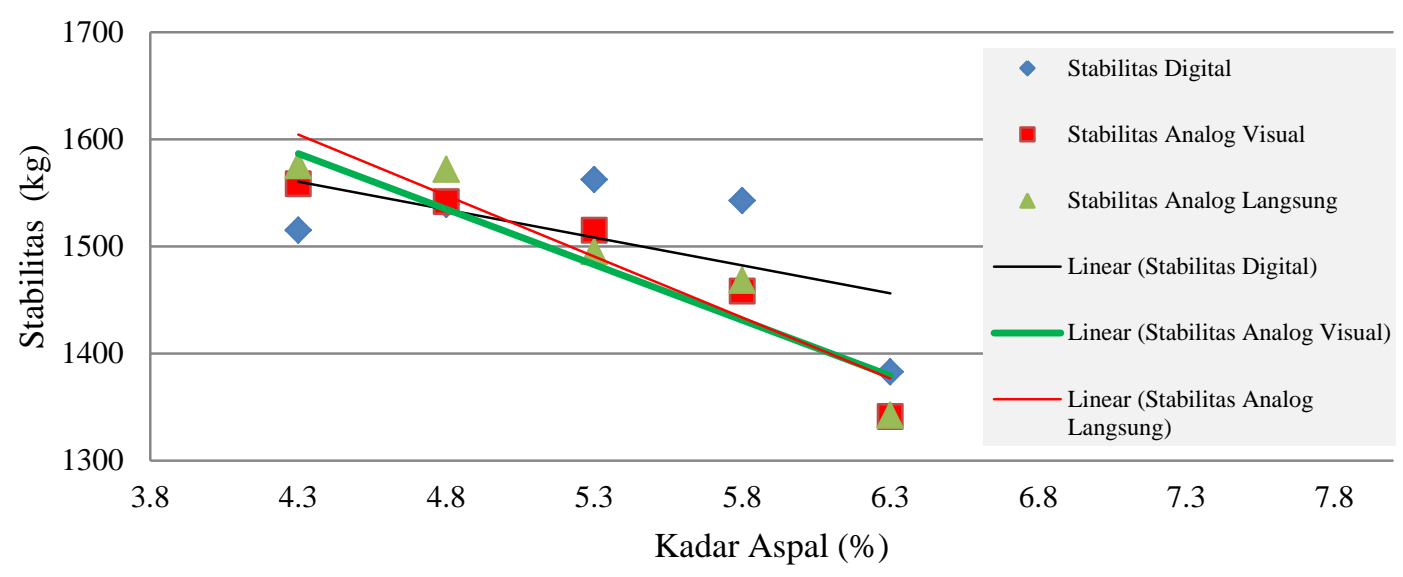

Gambar 3. Perbandingan Nilai Stabilitas Alat Uji Analog dan Digital

Gambar 3 diatas menunjukkan bahwa rata-rata nilai Stabilitas hasil pengujian menggunakan alat uji analog pengamatan langsung di dapatkan yaitu sebesar 1490,49 kg, alat uji analog dengan bantuan pengamatan perekaman video yaitu sebesar 1482,91, dan untuk uji digital nilainya lebih besar yaitu sebesar 1503,96 kg. Hal ini menunjukkan bahwa kekuatan menahan beban dalam beton aspal padat yang telah di uji menggunkan alat uji analog lebih rendah dari pada alat uji digital.

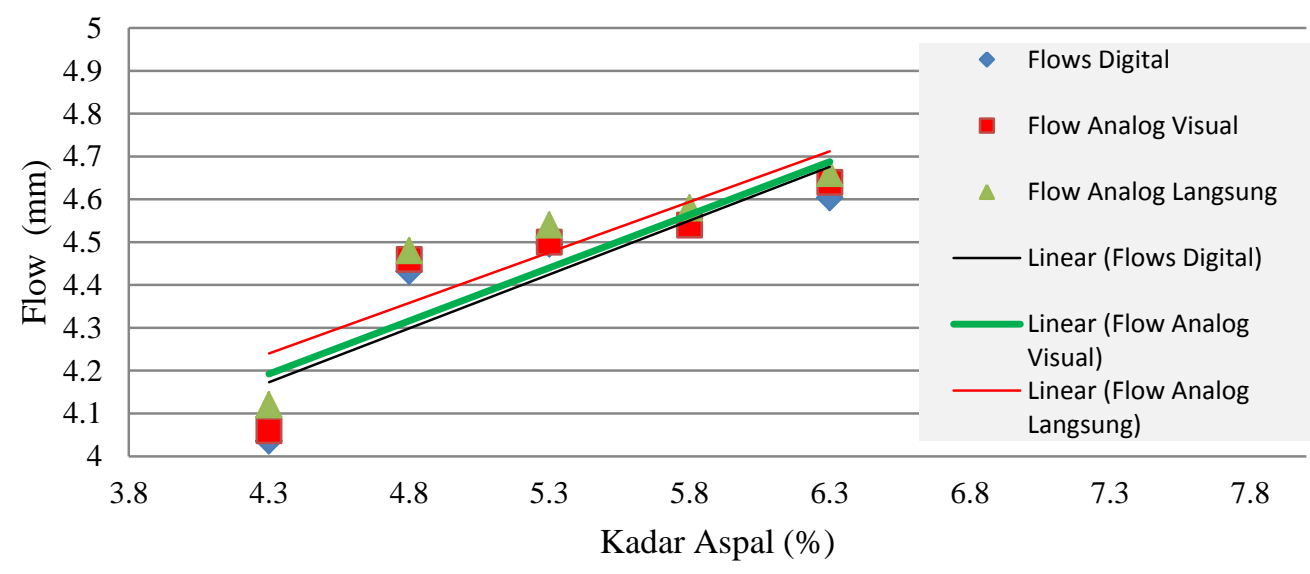

Gambar 4. Perbandingan Flow

Gambar 4 diatas menunjukkan bahwa rata-rata nilai flow hasil pengujian menggunakan alat uji analog pengamatan langsung yaitu sebesar $4,48 \mathrm{~mm}$, alat uji analog dengan bantuan pengamatan perekaman video yaitu sebesar $4,44 \mathrm{~mm}$, dan untuk alat uji digital yaitu sebesar 4,42 $\mathrm{mm}$. Hal ini menunjukkan bahwa kelelehan plastis akibat deformasi dalam beton aspal padat dan kemampuan beton aspal untuk menerima repetisi beban tanpa terjadinya retak yang telah di uji menggunkan alat uji analog lebih tinggi dari pada alat uji digital. 


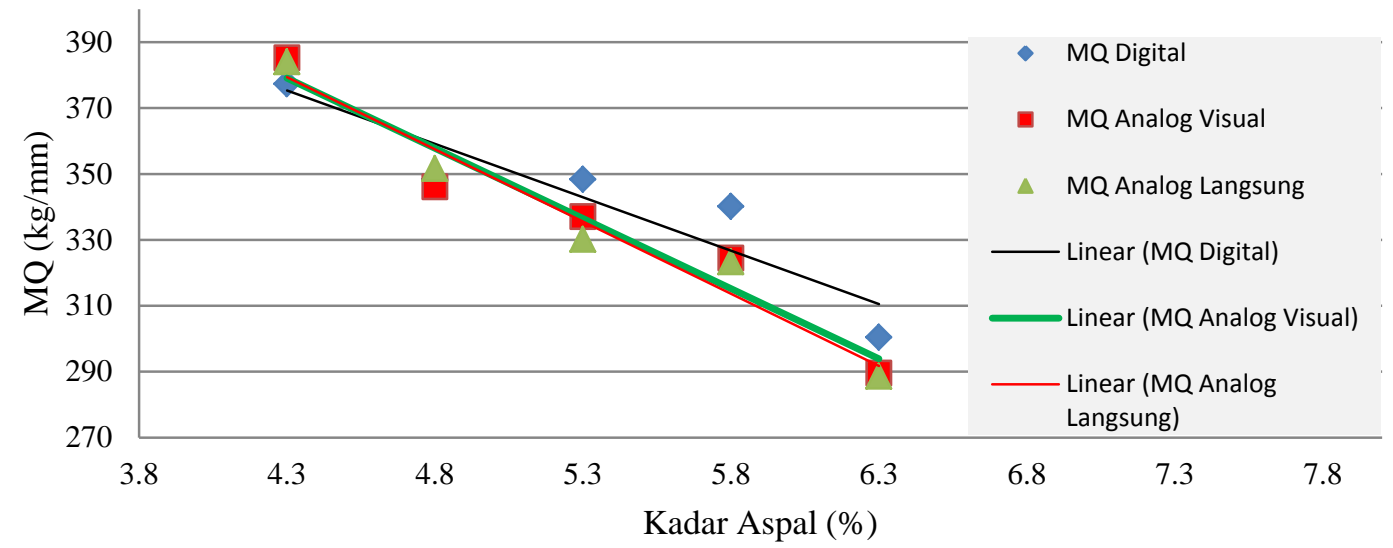

Gambar 5. Perbandingan $M Q$

Gambar 5 diatas menunjukkan bahwa rata-rata nilai $M Q$ hasil analisa dari stabilitas terhadap flow menggunakan alat uji analog pengamatan langsung yaitu sebesar 335,55 $\mathrm{kg} / \mathrm{mm}$, alat uji analog dengan bantuan pengamatan perekaman video yaitu sebesar 336,48 $\mathrm{kg} / \mathrm{mm}$, dan untuk alat uji digital yaitu sebesar 341,94 kg/mm. Hal ini menunjukkan bahwa kekakuan dalam beton aspal padat yang telah di uji menggunkan alat uji analog lebih tinggi dari pada alat uji digital.

\section{Uji Perbedaan Tiga Rata-rata}

Pengujian dilakukan untuk mengetahui apakah ada perbedaan secara signifikan atau tidak pada hasil pengujian Marshall menggunakan alat uji analog dan digital. Hasil pengujian hipotesis menggunakan Microsoft Excel ditunjukkan dalam tabel 2.

Tabel 2. Hasil Pengujian Perbedaan Tiga Rata-rata

\begin{tabular}{|c|c|c|c|c|c|c|c|c|c|c|c|c|}
\hline \multirow[t]{2}{*}{ No } & \multirow{2}{*}{$\begin{array}{c}\text { Karak- } \\
\text { teristik } \\
\text { Marshall }\end{array}$} & \multirow{2}{*}{$\begin{array}{c}\text { Jumlah } \\
\text { Benda } \\
\text { Uji }\end{array}$} & \multicolumn{2}{|c|}{$\begin{array}{l}\text { Uji Analog } \\
\text { Langsung }\end{array}$} & \multicolumn{2}{|c|}{$\begin{array}{c}\text { Uji Analog } \\
\text { Perekaman } \\
\text { Video }\end{array}$} & \multicolumn{2}{|c|}{ Alat Uji Digital } & \multirow[t]{2}{*}{ Alfa } & \multirow{2}{*}{$\begin{array}{c}\text { F } \\
\text { hitung }\end{array}$} & \multirow{2}{*}{$\underset{\text { kritis }}{F}$} & \multirow[t]{2}{*}{ Ket } \\
\hline & & & $\begin{array}{c}\text { Rata- } \\
\text { rata }\end{array}$ & Deviasi & $\begin{array}{l}\text { Rata- } \\
\text { rata }\end{array}$ & Deviasi & $\begin{array}{l}\text { Rata- } \\
\text { rata }\end{array}$ & Deviasi & & & & \\
\hline 1 & Stabilitas & 5 & 1490,49 & 95,26 & 1482,91 & 87,93 & 1508,36 & 72,18 & 0,05 & 0,0785 & 0,89 & terima \\
\hline 2 & Flow & 5 & 4,48 & 0,21 & 4,44 & 0,22 & 4,42 & 0,23 & 0,05 & 0,0726 & 0,89 & terima \\
\hline 3 & MQ & 5 & 335,55 & 35,34 & 336,48 & 34,71 & 342,93 & 27,64 & 0,05 & 0,0553 & 0,89 & terima \\
\hline
\end{tabular}

Dari hasil analisa dari pengujian dengan taraf kesalahan $5 \%$ menunjukkan nilai $\mathrm{f}_{\text {hitung }}$ pada setiap hasil pengujian lebih kecil dari $\mathrm{f}_{\text {tabel }}(3,89)$. Untuk kaidah keputusannya adalah jika $\mathrm{f}$ hitung $\geq \mathrm{f}_{\text {tabel }}$ maka ada perbedaan secara signifikan, jika $\mathrm{f}$ hitung $\leq \mathrm{f}_{\text {tabel }}$ maka tidak ada perbedaan secara signifikan. Dari hasil perhitungan diperoleh data $\mathrm{f}_{\text {hitung }} \leq \mathrm{f}_{\text {tabel. }}$. Jadi tidak terdapat perbedaan rata-rata hasil pengujian secara signifikan pada hasil pengujian menggunakan alat uji analog dan digital. 


\section{Pendugaan Hasil Pengujian}

Pendugaan hasil pengujian dilakukan untuk mendapatkan pendugaan terhadap parameter berdasarkan suatu interval mana kita harapkan dengan keyakinan tertentu parameter itu akan terletak. Pendugaan hasil pengujian ditunjukkan dalam tabel 3.

Tabel 3. Pendugaan Hasil Pengujian

\begin{tabular}{ccccccccccc}
\hline No & $\begin{array}{c}\text { Karakteristik } \\
\text { Marshall }\end{array}$ & \multicolumn{2}{c}{$\begin{array}{c}\text { Alat Uji Analog } \\
\text { (Pengamatan } \\
\text { Langsung) }\end{array}$} & $\begin{array}{c}\text { Alat Uji Analog } \\
\text { (Pengamatan } \\
\text { Perekaman Video) }\end{array}$ & \multicolumn{2}{c}{ Alat Uji Digital } \\
\hline 1 & Stabilitas & 1405,70 & - & 1575,27 & 1404,65 & - & 1561,17 & 1444,12 & - & 1572,60 \\
2 & Flow & 4,29 & - & 4,66 & 4,24 & - & 4,64 & 4,22 & - & 4,63 \\
3 & MQ & 304,10 & - & 367,00 & 305,60 & - & 367,37 & 318,33 & - & 367,53 \\
\hline
\end{tabular}

Berdasarkan tabel diatas nilai pendugaan hasil pengujian pada setiap karakteristik Marshall sudah didapatkan melalui analisa data dari hasil pengujian benda uji. Dapat diketahui bahwa secara umum selisih nilai batas atas dan batas bawah nilai pendugaan hasil pengujian pada alat uji digital lebih kecil dari pada alat uji analog. Hal ini menunjukkan bahwa tingkat konsistensi alat uji digital lebih baik daripada alat uji analog, terbukti dari nilai standart deviasi alat uji digital lebih kecil daripada alat uji analog, Akan tetapi untuk nilai standart deviasi flow pada digital lebih besar daripada analog. Namun perbedaan tersebut tidak berpengaruh secara signifikan menurut uji statistik.

\section{PENUTUP}

\section{Kesimpulan}

Berdasarkan analisa menunjukkan bahwa, tidak terdapat perbedaan secara signifikan pada hasil pengujian karakteristik Marshall yang di uji dengan alat uji analog secara langsung, uji analog pengamatan perekaman video, dan digital. Dan hasil ketiga pengujian ini bisa di katakan sama menurut uji statistik.

Untuk hasil pendugaan parameter karakteristik Marshall didapatkan nilai sebagai berikut : untuk alat uji analog pengamatan langsung menghasilkan stabilitas $(\mathrm{kg})=1405,70$ 1575,27; Flow $(\mathrm{mm})=4,29-4,66 ; M Q(\mathrm{~kg} / \mathrm{mm})=304,10-367,00$. Alat uji analog pengamatan perekaman video menghasilkan stabilitas $(\mathrm{kg})=1404,65-1561,17$; Flow $(\mathrm{mm})$ $=4,24-4,64 ; M Q(\mathrm{~kg} / \mathrm{mm})=305,60-367,37$. untuk alat uji digital menghasilkan stabilitas $(\mathrm{kg})=1444,12-1572,60 ;$ Flow $(\mathrm{mm})=4,22-4,64$; $M Q(\mathrm{~kg} / \mathrm{mm})=318,33-367,53$.

\section{Ucapan Terima Kasih}

Terima kasih disampaikan kepada Laboratorium Transportasi - Jurusan Teknik Sipil Fakultas Teknik Universitas Jember yang telah menyediakan peralatan selama penelitian hingga selsai. 


\section{DAFTAR RUJUKAN}

Aditama, A.T., Sulistyono, S., dan Badriani, R.E. 2014. Characteristics of Marshall on AC-BC Use the Analog and Digital Test Equipment. Prosiding Simposium FSTPT 17 Universitas Jember, Jember

Departemen Pekerjaan Umum. 1987. Petunjuk Perencanaan Tebal Perkerasan Lentur Jalan Raya Dengan Metode Analisa Komponen. Jakarta: Yayasan Badan Penerbit Pekerjaan Umum.

Departemen Pekerjaan Umum. 2007. Rancangan Spesifikasi Umum Bidang Jalan Jembatan. Divisi VI Perkerasan Beraspal. Jakarta.

DPU Bina Marga. 1999. Pedoman Perencanaan Campuran Beraspal dengan Pendekatan Kepadatan Mutlak. Penerbit: PT. Mediatama Saptakarya.

Putri, Ajeng Miranti 2010. Laboratory On The Durability Characteristics (Moisture Damage Evaluation) Of Asphalt Concrete Wearing Couse Utilizing Bantak And Clereng As Aggregate (Using Marshall Methods). Yogyakarta. Journal of the Easten Asia Society for Transportation Studies, Vol. 8. Universitas Gadjah Mada

Riduwan dan Sunarto. 2013. Pengantar Statistika Untuk Penelitian: Pendidikan, Sosial, Komunikasi, Ekonomi, dan Bisnis. Bandung: Alfabeta.

Sukirman, S. 2003. Beton Aspal Campuran Panas. Jakarta: Granit.

Supranto, J. 2009. Statistik Teori dan Aplikasi Jilid 7. Jakarta: Erlangga.

Zulfikar, G., Sulistyono, S., dan Hayati N.N. 2014. Perbandingan Nilai Stabilitas Dan Flow Campuran AC-WC Pada Pengujian Marshall Menggunakan Alat Uji Digital Dan Analog. Prosiding Simposium FSTPT 17 Universitas Jember, Jember 